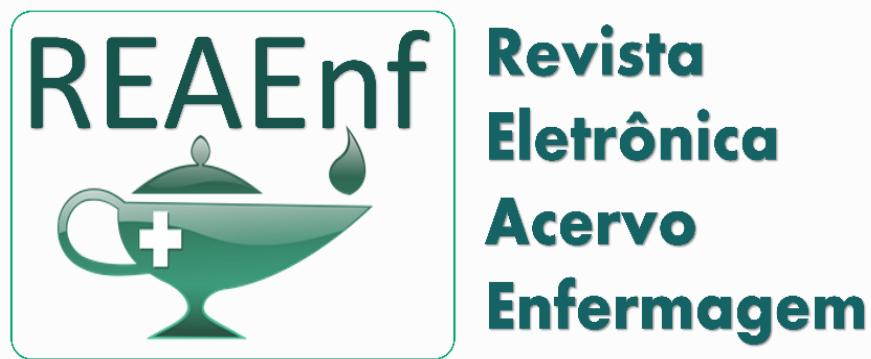

REVISÃO BIBLIOGRÁFICA

Recebido em: 7/2020

Aceito em: 8/2020

Publicado em: 10/2020

\title{
Depressão pós-parto: atuação do enfermeiro
}

\author{
Post-delivery depression: nurse's performance
}

Depresión post-entrega: rendimiento de la enfermera

\begin{abstract}
Almira Silva Justen Monteiro ${ }^{1 *}$, Daiane da Silva Fiuza Carvalho², Eliana Rosa da Silva1, Paula Mascarenhas Castro ${ }^{1}$, Ricardo Henrique da Silva Portugal ${ }^{1}$.
\end{abstract}

Resumo: O objetivo deste trabalho foi listar os cuidados do enfermeiro às mulheres com depressão pós-parto e suas repercussões psicossociais. Trata-se de um estudo bibliográfico com abordagem qualitativa e descritiva. A coleta de dados foi realizada buscando-se trabalhos semelhantes nas bases de dados acadêmicos-científicos SciELO (Scientific Eletronic Library Online) e LILACS (Literatura Latino-Americana e do Caribe em ciências da saúde). Quanto ao cuidado de enfermagem junto a puérpera com DPP, os estudos relatam que a atuação do enfermeiro junto a puérpera normalmente volta-se a realização do rastreamento da depressão, no acompanhamento de sua evolução nos atendimentos psicoterapêuticos individuais, grupais, nas ações educativas orientativas prestadas a este público e a seus familiares, sobretudo esclarecendo as medidas interventivas que são necessárias para garantir o bem estar da mãe e do bebê. Este trabalho pode contribuir com o conhecimento sobre a temática que se espera que reflita em ações concretas no acompanhamento e assistência a este grupo de mulheres, analisado um diagnóstico precoce da depressão pós-parto no período da gestação e o puerperal, e a responsabilidade que o profissional tem em perceber esse distúrbio em suas consultas de enfermagem com esta mulher, e também através de relatos de familiares.

Palavras-chave: Depressão pós-parto, Cuidados de enfermagem, Psicossociais.

\begin{abstract}
The objective this work is list the nurse's care for women with postpartum depression and its psychosocial repercussions. This is a bibliographic study with a qualitative and descriptive approach. Data collection was carried out looking for similar works in the academic-scientific databases SciELO (Scientific Electronic Library Online) and LILACS (Latin American and Caribbean Literature in health sciences). Regarding the nursing care with the puerperal woman with PPD, studies report that the nurse's performance with the puerperal woman usually focuses on tracking depression, in monitoring its evolution in individual and group psychotherapeutic care in educational actions guidelines provided to this audience and their families, especially clarifying the intervention measures that are necessary to ensure the well-being of the mother and baby. This work can contribute to the knowledge on the theme that is expected to reflect in concrete actions in monitoring and assisting this group of women, analyzing an early diagnosis of postpartum depression during pregnancy and the puerperal period, and the responsibility that the professional has in perceiving this disorder in his nursing consultations with this woman, and also through of family reports.
\end{abstract}

Keywords: Postpartum depression, Nursing care, Psychosocial.

\footnotetext{
${ }_{1}^{1}$ Centro Universitário Estácio da Bahia, Salvador - BA. *E-mail: almira.enfftc@gmail.com

${ }^{2}$ Hospital Municipal Dr. Albino Leitão. São Sebastião do Passé - BA.
} 
Resumen: El objetivo de este trabajo fue enumerar la atención de enfermería para mujeres con depresión posparto y sus repercusiones psicosociales. Es un estudio bibliográfico con enfoque cualitativo y descriptivo. La recopilación de datos se realizó buscando trabajos similares en las bases de datos académico-científicas SciELO (Scientific Electronic Library Online) y LILACS (Literatura latinoamericana y caribeña en ciencias de la salud). con respecto a la atención de enfermería con la mujer puerperal con DPP, los estudios informan que el desempeño de la enfermera con la mujer puerperal generalmente se centra en el seguimiento de la depresión, en el seguimiento de su evolución en la atención psicoterapéutica individual y grupal en acciones educativas pautas proporcionadas a esta audiencia y sus familias, especialmente aclarando las medidas de intervención que son necesarias para asegurar el bienestar de la madre y el bebé. Este trabajo puede contribuir al conocimiento sobre el tema que se espera que se refleje en acciones concretas. para monitorear y asistir a este grupo de mujeres, analizar un diagnóstico temprano de depresión posparto durante el embarazo y el período puerperal, y la responsabilidad que tiene el profesional para percibir este trastorno en sus consultas de enfermería con esta mujer, y también a través de de informes familiares.

Palabras clave: Depresión posparto, Cuidado de enfermera, Psicosocial

\section{INTRODUÇÃO}

A depressão pode ser conceituada como patologia que afeta todo o organismo, que compromete o físico, o humor e, em consequência, o pensamento e os relacionamentos sociais. Trata-se de uma doença com alteração das expressões e humores, não sendo sinal de fraqueza, ausência de pensamentos positivos ou uma condição que se supera apenas pela força de vontade ou esforço. Pode se manifestar de diversas maneiras, constando em todos os tipos, comprometimento de ânimo, principalmente, nas atividades que geram prazer (ALVES AM, et al 2007).

Muita pesquisa sobre saúde mental, relacionadas ao parto, tem levado a mudanças na concepção específica de depressão pós-parto (DPP). Isto acontece pela consideração de um extenso leque de transtornos depressivos e ansiosos que podem surgir no período perinatal. Trata-se de uma mudança que está vinculada ao crescente reconhecimento da necessidade de prevenção e intervenção precoce nesse período específico (BRASIL, 2012).

Neste sentido, o conjunto de sintomas da DPP inclui, dentre outros, irritabilidade, frequência de choro, sentimentos de desamparo ou desesperança, falta de energia e motivação, desinteresse sexual, alterações alimentares e do sono, sensação de ser incapaz de lidar com novas situações e queixas psicossomáticas. No corpo, uma mãe com DPP pode apresentar sintomas de cefaleia, dores nas costas, erupções vaginais e dor abdominal, sem causa orgânica aparente (BERETTA MIR, 2008).

A DPP vai além das primeiras semanas após o nascimento, esta apresenta um quadro clínico específico e pode trazer prejuízos ao bebê, a mãe, a família e ao vínculo entre eles. Ocorre normalmente na primeira gestação devido ao sentimento de incapacidade de cuidar do filho, acomete principalmente mulheres que não tem estrutura familiar estável ou que teve uma gestação com complicações. Pode acontecer com frequência após um aborto ou em casos de natimortos (BERETTA MIR, 2008).

Segundo Moraes IGS (2006), uma em cada cinco mulheres desenvolvem depressão no puerpério. Desta forma, o Brasil possui uma alta prevalência na patologia, que em 2001 passou a ser considerado pela OMS um problema de saúde pública. Atualmente, 15 a $29 \%$ das puérperas desenvolvem a DPP, chegando à incidência de $30 \%$ em adolescentes (GIL AC, 2010). Diante deste quadro há uma alta relevância para que estudos outros proporcionem questionamentos e se dediquem a pesquisas sobre tal assunto, com o objetivo de sensibilizar a equipe multiprofissional e família para a problemática (GIL AC, 2010).

Em que se refere ao cuidado de enfermagem esse representa imprescindível papel na promoção da qualidade de vida e saúde da mulher com DPP e deve conduzir-se inicialmente a realização de rastreamento, e acompanhamento de sua evolução e orientação terapêutica (GIL AC, 2010). O enfermeiro deve estar preparado para detectar os casos e encaminhá-los aos profissionais especializados para atendimento. Logo,

REAEnf/EJNC | Vol. 4 | e4547 | DOI: https://doi.org/10.25248/REAenf.e4547.2020 Página 2 de 9 
a equipe multidisciplinar irá contribuir para a melhora e cura da DPP. Este fato constitui-se relevante na realização da pesquisa (SOBREIRA N e PESSOA CG, 2012)

Um trabalho desta natureza se justifica na medida em que aborda um problema de ordem psicossocial e também uma condição que assume várias formas, além de poder permanecer sem diagnóstico por longos períodos de tempo. Desde que a conscientização sobre a DPP surgiu pela primeira vez no final dos anos 80 , muitos estudos foram realizados sobre a prevalência, fatores de risco e taxas de tratamentos bem-sucedidos entre a população mundial (SANTOS Jr HPO, 2013).

Estudos com esse viés também são importantes para se acumular dados, informações e conhecimentos importantes que esclarecem a difusão e magnitude desse problema global de saúde mental. Assim, as estatísticas de vários estudos e fontes, abrangendo as últimas décadas não trazem as taxas exatas de depressão pós-parto, mas existem alguns números geralmente concordados sobre o número de mulheres que sofrem de DPP anualmente e estes dão conta de que aproximadamente $70 \%$ a $80 \%$ das mulheres a experimentarão em diferentes graus de acometimento (BAPTISTA MN, et al. 2006; SOBREIRA N e PESSOA CG, 2012).

Muitas mulheres experimentam a condição mais grave de DPP ou uma condição relacionada a ela. Assim, a taxa relatada de depressão clínica pós-parto entre novas mães é de $10 \%$ a $20 \%$ e 1 em cada 7 mulheres podem apresentar DPP no ano subsequente ao parto. Entre os milhões de nascidos vivos que ocorrem a cada ano, isso equivale a centenas de milhares de diagnósticos apenas por nascidos vivos.

Da mesma forma, muitas mulheres que abortam ou têm natimortos também apresentam sintomas de DPP como uma questão global e outros vários estudos ainda que a DPP é muito mais comum do que essas estatísticas revelam, pois médicos especialistas acreditam que a taxa de DPP pode ser pelo menos o dobro do que é realmente relatado e diagnosticado (FONSECA VR, et al. 2010). Outro fator que justifica um estudo sobre DPP, é que ela pode afetar pessoas de todas as raças, etnias, culturas e origens educacionais ou econômicas.

Diante do exposto, tem-se o objetivo de listar os cuidados do enfermeiro às mulheres com DPP e suas repercussões psicossociais. Tal busca se situa na confluência entre alterações emocionais, frustração e insegurança pessoal, antes durante e depois do parto, envolvendo família e sociedade em torno dos cuidados de enfermagem para a satisfação das mães em potencial.

\section{MÉTODOS}

Trata-se de um estudo bibliográfico com abordagem qualitativa de acordo com Gil AC (2010), a pesquisa bibliográfica é desenvolvida com base em material que já foi elaborado artigos científicos, cujo objetivo é revisar a literatura existente, identificando assim o estado da arte no que se refere a temática do estudo.

Sendo assim, a principal característica de abordagem qualitativa é trazer à tona discussões a respeito de algum fato ou fenômeno, buscando avaliá-lo a partir de teorias, ou da própria descrição lógica em que este se apresenta. Constitui-se em um estudo mais aprofundado de um determinado assunto, por não está presa a meras descrições, mas buscar porquês, condições, avaliar o tempo, o espaço, analisando de forma dinâmica uma determinada realidade.

Foram traçados então critérios de inclusão e exclusão de trabalhos publicados como prática padrão e necessária na elaboração de protocolos da pesquisa, como aqueles que incluem as características da problemática do estudo (Figura 1).

O levantamento de dados foi realizado através de artigos científicos que abordam o tema. Os critérios de inclusão foram para artigos relacionados com o objetivo e a problemática da pesquisa, e que tenha sido publicado (2006-2019), na língua portuguesa, tendo uma apresentação consistente dos dados para discussão do manuscrito. A coleta foi realizada nas seguintes bases de dados acadêmico-científicos: SciELO (Scientific Electronic Library Online) e LILACS (Literatura Latino-Americana e do Caribe em Ciências da Saúde). 
Figura 1 - Fluxograma de inclusão/exclusão no trabalho de investigação.

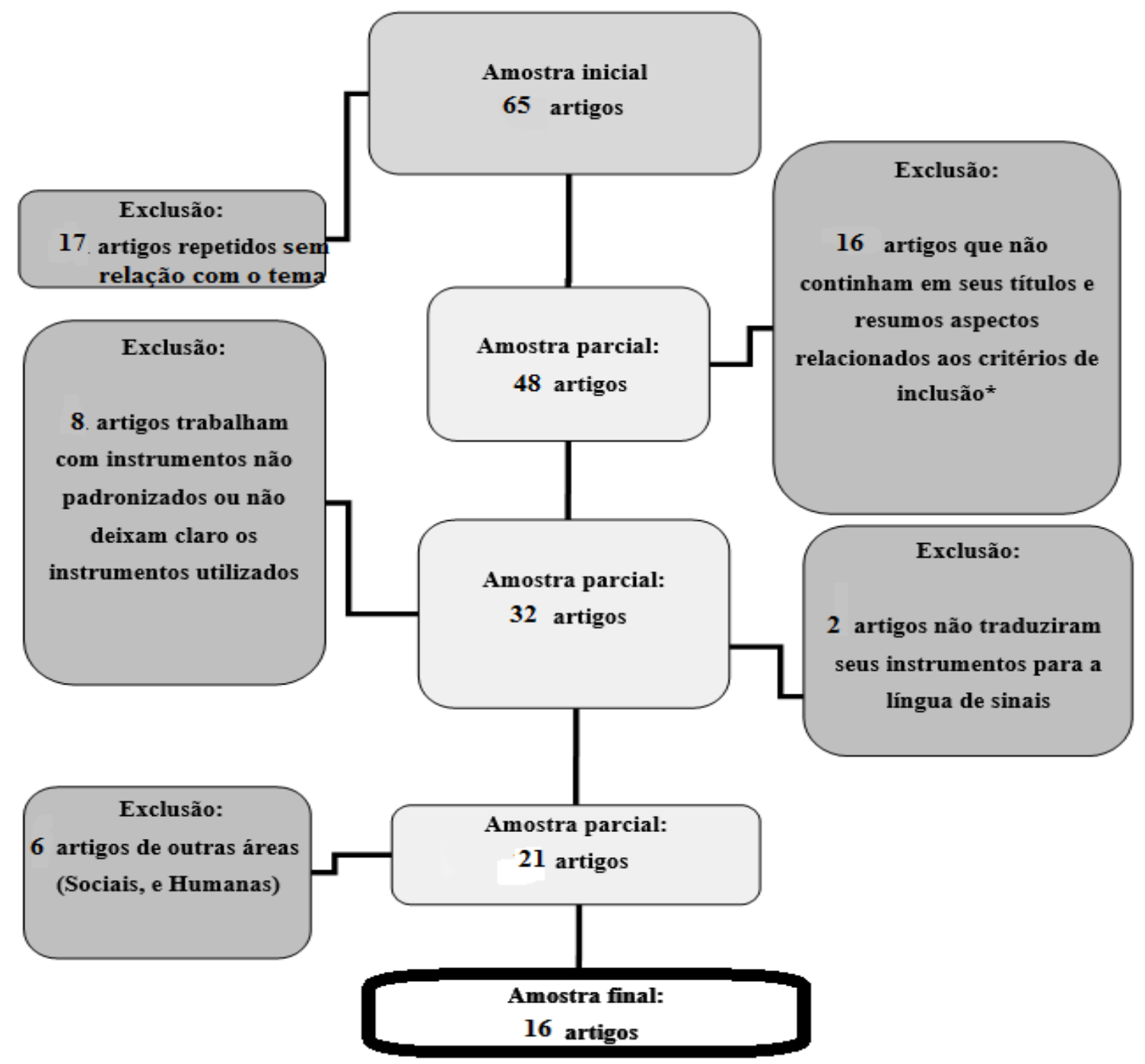

Fonte: MONTEIRO ASJ, et al., 2020.

Foram utilizadas as palavras-chaves existentes: "Depressão pós-parto", "Cuidados de enfermagem", "Psicossociais". A consulta a esses termos ocorreu por se tratar de uma linguagem de indexação que colabora na busca e recuperação de conteúdos científicos da área de saúde, por meio das informativas que existem na Biblioteca Virtual em Saúde (BVS) (BIREME, 2017).

Encontrados 65 artigos científicos, utilizados 16 artigos, e 49 foram excluídos por não ter relação com a temática, sendo que foram publicados nos últimos 13 anos, através da pesquisa de artigos científicos na Biblioteca Virtual em Saúde, utilizando a base de dados eletrônica SciElo, Descritores em Ciências da Saúde (DeCS), BIREME e LILACS, conforme o Quadro 1.

Os princípios éticos serão contemplados no desenvolvimento deste estudo para proteger os direitos das participantes durante o processo de coleta de dados. Esta pesquisa está de acordo com resolução 466/2012, do Conselho Nacional de Saúde que aprovou as diretrizes e normas regulamentadoras de pesquisas envolvendo seres humanos. Segundo esta resolução, as pesquisas com seres humanos devem atender aos fundamentos éticos e científicos pertinentes (BRASIL, 2012). 
Quadro 1 - Referências selecionadas pelo critério de inclusão/exclusão.

\begin{tabular}{|c|c|c|}
\hline Autor e ano & Objetivo & Principais resultados \\
\hline $\begin{array}{l}\text { ALVES AM, et al., } \\
2007 .\end{array}$ & $\begin{array}{l}\text { Relacionar os cuidados de enfermagem } \\
\text { com mães primíparas, desvendando o } \\
\text { processo de transição para o papel } \\
\text { materno. }\end{array}$ & $\begin{array}{l}\text { Em termos de período puerperal e enfrentamento de papéis daí advindos, as atividades do } \\
\text { enfermeiro está na possibilidade de se atura na compreensão da transição vivencial para seu } \\
\text { novo papel materno. Isto inclui novos sentimentos, novas diligências, outras barreiras e } \\
\text { mudanças de pensamento. }\end{array}$ \\
\hline $\begin{array}{l}\text { BERETTA MIR, } \\
\quad 2008 .\end{array}$ & $\begin{array}{l}\text { Analisar a associação Tristeza/depressão } \\
\text { na mulher no período gestacional e/ou } \\
\text { puerperal }\end{array}$ & $\begin{array}{l}\text { Recomenda o suporte do marido e familiares e assinala que a tristeza e/ou DPP se impõe na } \\
\text { vida da puérpera na medida em que estes suportes não são fortes o bastante. Desta forma, as } \\
\text { gestantes de maior risco são aquelas estão sob más condições de adaptação ao papel, situação } \\
\text { socioeconômica desfavorável e instabilidade familiar. Isto mostra a importância das UBS e dos } \\
\text { enfermeiros para o enfrentamento (identificação precoce e acompanhamento). }\end{array}$ \\
\hline $\begin{array}{l}\text { BAPTISTA MN, et } \\
\text { al., } 2006 .\end{array}$ & $\begin{array}{l}\text { Relacionar suporte social, depressão e } \\
\text { ansiedade em gestantes. }\end{array}$ & $\begin{array}{l}\text { Há uma correspondência positiva entre a escala de depressão, estado e traço de ansiedade. } \\
\text { Além disso, há também correspondência negativa entre as escalas de depressão e suporte } \\
\text { social, ansiedade traço e estado com suporte social. Os dados apontam para a importância do } \\
\text { suporte social nesse período. }\end{array}$ \\
\hline BRASIL, 2012. & $\begin{array}{l}\text { Verificar a inteiração das disposições sobre } \\
\text { diretrizes e normas regulamentadoras das } \\
\text { pesquisas envolvendo seres humanos. }\end{array}$ & $\begin{array}{l}\text { Utilizado para verificar a participação em pesquisas científicas com seres humanos contendo } \\
\text { as diretrizes e normas regulamentadoras de pesquisas em saúde humana e sua aprovação. }\end{array}$ \\
\hline $\begin{array}{l}\text { FONSECA MO, et } \\
\text { al. } 2009 .\end{array}$ & $\begin{array}{l}\text { Investigar os fatores indicativos da DPP em } \\
\text { dois grupos de puérperas. }\end{array}$ & $\begin{array}{l}\text { Variáveis como número de filhos, paridade e apoio da família e/ou amigos apresentaram } \\
\text { associação com a ocorrência de DPP e deve ser incluída nos serviços de saúde em que } \\
\text { enfermeiros prestam atendimento a gestantes e puérperas. }\end{array}$ \\
\hline $\begin{array}{l}\text { FONSECA VR, et } \\
\quad \text { al., } 2010\end{array}$ & $\begin{array}{l}\text { Relacionar DPP e disponibilidade } \\
\text { emocional materna. }\end{array}$ & $\begin{array}{l}\text { Houve prevalência de DPP em uma amostra de } 28 \% \text { das participantes. Não se encontrou } \\
\text { diferença significativa na relação mãe-criança no grupo com e sem depressão. Além disso, foi } \\
\text { encontrada correlação positiva entre sensibilidade materna e escolaridade e entre sensibilidade } \\
\text { e certas dimensões de apoio social e estilo de relacionamento. }\end{array}$ \\
\hline GIL AC, 2010. & Como elaborar projetos de pesquisa & $\begin{array}{l}\text { As melhores abordagens para cada tipo de pesquisa, etapas, a problemática e conhecimentos } \\
\text { que contribuem de para a condução eficaz da construção de um projeto de pesquisa a partir do } \\
\text { projeto inicial. }\end{array}$ \\
\hline $\begin{array}{l}\text { NOELEN- } \\
\text { HOEKSEMA S, } \\
2010 .\end{array}$ & $\begin{array}{l}\text { Identificar, sob as bases das teorias das } \\
\text { diferenças de gênero, a depressão unipolar } \\
\text { sob o viés epidemiológico. }\end{array}$ & $\begin{array}{l}\text { É proposta uma explicação do conjunto de respostas para as diferenças de sexo na depressão } \\
\text { em que, independentemente da fonte inicial de um episódio depressivo (isto é, biológico ou } \\
\text { psicológico), as respostas mais ativas dos homens ao humor negativo podem ser mais } \\
\text { adaptáveis, em média, do que as respostas menos ativas e mais ruminativas das mulheres. }\end{array}$ \\
\hline
\end{tabular}

REAEnf/EJNC | Vol. 4 | e4547 | DOI: https://doi.org/10.25248/REAenf.e4547.2020 Página 5 de 9 


\begin{tabular}{|c|c|c|}
\hline $\begin{array}{l}\text { MINAYO MCS, } \\
2010 .\end{array}$ & $\begin{array}{l}\text { Estabelecer métodos criativos para a } \\
\text { pesquisa em ciências da saúde. }\end{array}$ & $\begin{array}{l}\text { Escolha do design da pesquisa combinando teoria, método e criatividade, itens salutares para } \\
\text { produzirem conhecimentos e possibilitar a sondagem da realidade e os segredos da realidade. }\end{array}$ \\
\hline $\begin{array}{l}\text { MORAES IGS, et } \\
\quad \text { al } 2006 .\end{array}$ & $\begin{array}{l}\text { Analisar os fatores associados à } \\
\text { prevalência da depressão pós-parto }\end{array}$ & $\begin{array}{l}\text { Houve a prevalência de DPP na ordem de 19,1\%. Variáveis como familiar (OR=5,24; IC 95\%: } \\
2,00-13,69) \text {, preferência pelo sexo da criança (meninos: OR=3,49; IC 95\%: } 1,76-6,93) \text { e pensar } \\
\text { em interromper a gestação (OR=2,52; IC 95\%: 1,33-4,76), evidenciaram a associação com a } \\
\text { ocorrência DPP. }\end{array}$ \\
\hline $\begin{array}{l}\text { RIBEIRO WG e } \\
\text { ANDRADE M, } \\
2009 \text {. }\end{array}$ & $\begin{array}{l}\text { Estabelecer o papel do enfermeiro na } \\
\text { prevenção da Depressão Pós-Parto }\end{array}$ & $\begin{array}{l}\text { Destaca a importância da assistência de enfermagem à mulher durante o pré-natal e puerpério, } \\
\text { pois esse cuidado de acompanhamento durante a gestação e no pós-parto, contribui } \\
\text { positivamente na qualidade de vida de mãe e filho e favorece o diagnóstico precoce da DPP. }\end{array}$ \\
\hline $\begin{array}{l}\text { SANTOS Jr HPO, } \\
2013 .\end{array}$ & $\begin{array}{l}\text { Traçar a trajetória de mulheres brasileiras } \\
\text { na depressão pós-parto. }\end{array}$ & $\begin{array}{l}\text { Compreensão de que a trajetória das mulheres na experiência de depressão as leva a vivenciar } \\
\text { uma maternidade fora dos padrões idealizados. A consequência é que se modifica a forma } \\
\text { como elas entendiam anteriormente a própria identidade. Assim, identidade e maternidade são } \\
\text { abaladas e pensamentos negativos (machucar os filhos, por exemplo) se instalam. Os sintomas } \\
\text { depressivos afetam também a capacidade individual das mulheres e a própria percepção sobre } \\
\text { si mesmas, o que por si só, gera a necessidade por assistência (Profissional e familiar) e o } \\
\text { tratamento psicofarmacológico foram as principais estratégias na tentativa de recuperar a } \\
\text { saúde. }\end{array}$ \\
\hline $\begin{array}{l}\text { SCHARDOSIM JM } \\
\text { e HELDT E, } 2011 .\end{array}$ & $\begin{array}{l}\text { Revisar sistematicamente as Escalas de } \\
\text { rastreamento para depressão pós-parto. }\end{array}$ & $\begin{array}{l}\text { A DPP foi encontrada entre } 8,8 \text { a } 40 \% \text { da amostra dos estudos revisados e a Edinburg } \\
\text { Depression Postpartum Scale (EDPS) e outras escalas de identificação da DPP podem ser } \\
\text { ferramentas facilitadoras para o enfermeiro na assistência às mulheres puérperas. }\end{array}$ \\
\hline $\begin{array}{l}\text { SILVA FCS, et al., } \\
2010 .\end{array}$ & $\begin{array}{l}\text { Conhecer as interações entre mãe, filho e } \\
\text { família na DPP em puérperas. }\end{array}$ & $\begin{array}{l}\text { Identifica as principais alterações emocionais que foram relatadas como choro fácil e } \\
\text { nervosismo. As mulheres puérperas sentiam frustração e/ou inseguranças quanto ao exercício } \\
\text { da maternidade e familiares desconhecem o problema da DPP, a princípio. }\end{array}$ \\
\hline $\begin{array}{l}\text { SOBREIRA N e } \\
\text { PESSOA CG, } \\
\text { 2012. }\end{array}$ & $\begin{array}{l}\text { Estabelecer os cuidados e assistência de } \\
\text { Enfermagem na Detecção da Depressão } \\
\text { Pós-Parto. }\end{array}$ & $\begin{array}{l}\text { demonstrou-se que os profissionais de enfermeiros conheciam os fatores desencadeantes da } \\
\text { DPP, bem como implementavam atividades de prevenção e diagnóstico precoce, ainda que de } \\
\text { forma pouco sistêmica. Assinalou-se a necessidade de uma atuação multidisciplinar para essa } \\
\text { assistência específica. }\end{array}$ \\
\hline $\begin{array}{l}\text { VALENÇA CN e } \\
\text { GERMANO RM, } \\
\quad 2010 .\end{array}$ & $\begin{array}{l}\text { Analisar a prevenção da Depressão } \\
\text { Puerperal na Estratégia de Saúde da } \\
\text { Família. }\end{array}$ & $\begin{array}{l}\text { Obteve-se a colaboração da mulheres puérperas abordadas e houve uma interação proveitosa } \\
\text { por parte das mulheres com vários relatos de experiências pessoais sobre a DPP evidenciando } \\
\text { a que os sintomas da doença são mais comuns do que imagina e a falta de assistência familiar } \\
\text { e a busca pelo tratamento e ações educativas tendo em vista a prevenção. }\end{array}$ \\
\hline
\end{tabular}

Fonte: MONTEIROS ASJ, et al., 2020.

REAEnf/EJNC | Vol. 4 | e4547 | DOI: https://doi.org/10.25248/REAenf.e4547.2020 Página 6 de 9 


\section{RESULTADOS E DISCUSSÃO}

Quanto ao cuidado de enfermagem junto a puérpera com DPP, os estudos relatam que a atuação do enfermeiro junto a puérpera normalmente volta-se a realização do rastreamento da depressão, no acompanhamento de sua evolução nos atendimentos psicoterapêuticos individuais, grupais, nas ações educativas orientativas prestadas a este público e a seus familiares, sobretudo esclarecendo as medidas interventivas que são necessárias para garantir o bem estar da mãe e do bebê (ALVES AM, et al., 2007).

Corroborando com essas ideias, acrescentam que a equipe de enfermagem deve buscar a promoção de ações preventivas na rede pública, estimulando a mulher e seu companheiro na compreensão sobre as fases do puerpério, pois só assim é possível se dar condições para o controle desta patologia. Mas tal fato é um grande desafio, pois verifica-se que é exatamente na rede de atendimento a saúde que ainda existem várias lacunas no tocante a esse tipo específico de serviço (NOELEN-HOEKSEMA S, 2010).

Mencionam que o enfermeiro pela própria característica de seu trabalho é aquele que inicialmente estará em contato com a mulher durante o pré-natal, sendo essa etapa de imprescindível valor para detecção precoce da depressão. Para isso, deve ele estabelecer com a paciente uma relação de confiança, observar e anotar comportamentos que sejam suspeitos, e caso ela esteja deprimida estimular e oferecer atividades construtivas, acolher, atender, referenciar, compreender, observar se há indícios de ideias suicidas e orientar o encaminhamento psicológico. Nesse tocante, destacam os autores a importância de um atendimento sistematizado, a fim de melhor qualificar este tipo de assistência, que merece atenção especial (FONSECA VR, et al., 2010).

É importante enfatizar que a sistematização da assistência em enfermagem para ser adequada deveria primeiramente estar baseada nas competências profissionais da equipe de enfermagem, a qual além de intuição, dinamismo, julgamento clínico e autonomia, deveria também saber compreender a mulher em sua integralidade, cuidando-a de maneira individualizada e respeitando suas singularidades, crenças e valores, na medida em que não demonstre ser prejudicial a sua saúde (ALVES AM, et al., 2007).

De modo geral, o cuidar de enfermagem para ser adequado, deve estar pautado em uma forma de compreensão singular, em que os significados, vivências, experiências e a realidade psicossocial da paciente devem também ser fatores de analise, pois só assim será possível traçar estratégias que auxiliem de fato para que o plano terapêutico venha poder surtir os efeitos desejados (SANTOS Jr HPO, 2013).

Outra questão apontada na abordagem realizada pela enfermagem é a capacidade de identificar os riscos a que cada gestante está exposta. Pois uma gestante de baixo risco pode tornar-se de alto risco para a DPP e essa identificação dependerá de um monitoramento continuado que se faz necessário realizar junto a mulher a cada atendimento realizado, pois um meio necessário para o controle da patologia é a disseminação de ações de promoção ao controle e informações sobre a DPP na rede de atendimento em saúde (MINAYO MCS, 2010; SILVA FCS, et al., 2013).

Na prestação do cuidado a mulher em processo gestacional e puerperal, os profissionais de saúde, principalmente os enfermeiros, devem apreender a complexidade que envolve a DPP, não apenas seus aspectos clínicos como também os significados dessa experiência para a mulher e a sua família. Ressalta-se que o diagnóstico precoce e a instituição do tratamento são os meios de prevenir que a depressão se agrave. Assim, os enfermeiros atuantes na atenção básica podem fazer a diferença no tratamento da DPP auxiliando famílias no enfrentamento dessa doença (GIL AC, 2010).

Para trabalhar adequadamente é oportuno que o enfermeiro utilize estratégias preventivas, tais como a abordagem psicológica da mulher, o incentivo a presença do parceiro nas consultas pré-natal, realização de visitas domiciliares ou mesmo a formação de grupos de gestantes para educação em saúde (GIL AC, 2010).

Destacam-se o papel de programas psicoeducacionais como alternativas capazes de contribuir para redução dos casos de DPP. Destacam ainda que a capacitação específica em Saúde Materna e Obstétrica é um elemento importante na assistência prestada a esses pacientes, uma vez que terão estas maiores condições de oferecer suporte e orientações que se tornem necessárias (BAPTISTA MN, et al., 2006). 
A interação entre os profissionais de saúde e familiares pode transformar este momento em uma fase em que a paciente se sentirá mais firme e confiante para expressar seus sentimentos, sentindo-se acolhida e ajudada. Só assim pode-se proporcionar uma melhor superação das dificuldades que a Depressão Pós-Parto, já que seus maiores aliados são o descaso e a subestimação do sofrimento da mulher, quer pela equipe de saúde, quer pela família (RIBEIRO WG e ANDRADE M, 2009).

Nesse sentido, a constatação antecipada das fontes de risco inerentes à DPP, que é realizada através do acompanhamento das gestantes, é salutar para se falar em prevenção dos riscos e de suas reverberações na interação mãe-filho. Com isto se abre ao enfermeiro a possibilidade de auxiliar a puérpera e a sua família, principalmente se começar ainda durante a gestação e continuar no puerpério (RIBEIRO WG e ANDRADE $M, 2009)$. Em termos de limitações do estudo, uma avaliação crítica da amostra das pesquisas encontradas sugere várias limitações: Primeiro, a generalização dos resultados para todos os enfermeiros na prática clínica não é possível, pois houve uma falta de diversidade amostral nos estudos consultados e, na realidade, pode haver diferenças de gênero, escolaridade dos profissionais e até de região geográfica.

Assim, a replicação em uma amostra mais diversificada é garantida. Além disso, os estudos de viés de não resposta na percepção dos pacientes em relação à assistência de enfermagem não constatou o quanto ou a qualidade do uso de procedimentos de acompanhamento para aumentar a taxa de resposta positiva, o que altera as conclusões gerais (MINAYO MCS, 2010). Por outro lado, os pontos fortes desta pesquisa incluem uma amostra relativamente minerada entre muitas outras publicações, contendo descrições da atuação de enfermeiros, o estado da arte, de diversos contextos. Discute-se então, a partir de tais resultados, que a aceitação da triagem e do tratamento da depressão no pós-parto, conforme demonstrado aqui, é um precursor necessário, mas não suficiente, para a implementação. O estabelecimento de programas de triagem requer muitas etapas, incluindo educar a equipe, selecionar uma ferramenta de triagem e estabelecer um protocolo de triagem e fontes de referência.

Em um estudo de Noelen-Hoeksema S (2010), mesmo quando todos esses recursos estavam disponíveis, a triagem das mães quanto à depressão durante as visitas pediátricas ao filho não foi implementada imediatamente por toda a equipe: apenas $46 \%$ dos gráficos elegíveis incluíam um EPDS completo nos primeiros três meses desse programa por este autor citado. Por isso, a identificação de recursos de tratamento geralmente apresenta outro desafio significativo: Embora uma discussão completa sobre esse assunto esteja além do escopo deste artigo, é necessário levar em conta as opiniões dos enfermeiros sobre o aconselhamento realizado por eles e o que julgam ser relevante nesta questão.

Em muitos casos, os enfermeiros acreditam poder aconselhar efetivamente as mulheres pós-parto deprimidas, embora estejam divididos igualmente sobre quem e o quê deveria aconselhar, uma vez que a intervenção parece viável porque é desenvolvida especificamente para enfermeiros com pouca ou nenhuma experiência anterior em aconselhamento e o treinamento é breve e capitaliza as fortes habilidades de comunicação dos enfermeiros (FONSECA VR, et al. 2010).

Da mesma forma, como implicações clínicas sugere-se que profissionais da enfermagem em ambientes perinatais devem rastrear seus pacientes quanto à depressão, tanto como parte dos cuidados de uma mulher quanto durante os cuidados pediátricos de seus filhos, usando ferramentas de rastreamento de depressão personalizadas para mulheres perinatais estão disponíveis e incluem a Escala de Rastreamento de Depressão Pós-Parto e a Escala de Depressão Pós-natal de Edimburgo (SCHARDOSIM JM e HELDT E, 2011; BAPTISTA MN, et al., 2006).

Neste mesmo sentido, a implementação de uma triagem perinatal entregue pelo serviço de enfermagem exigirá programas educacionais para a equipe, bem como o estabelecimento de um protocolo de triagem e fontes de referência, o que é facilmente encontrado em sites que fornecem recursos educacionais que incluem amparo e treinamento para aprimorar a atenção primária à depressão pós-parto e bases como a MedEdPPD (NOELEN-HOEKSEMA S, 2010). Mesmo quando a triagem e o encaminhamento frequentemente destacam como barreira a falta de recursos de tratamento e/ou a relutância das mulheres em procurar um profissional de saúde mental, o aconselhamento prestado por enfermeiros, deve ser efetivamente buscado.

REAEnf/EJNC | Vol. 4 | e4547 | DOI: https://doi.org/10.25248/REAenf.e4547.2020 Página 8 de 9 


\section{CONSIDERAÇÕES FINAIS}

Diante da literatura analisada para a execução deste trabalho, pode-se dizer que ele contribui para a área de conhecimento sobre a DPP e que tem etiologia multifatorial atingindo um significativo grupo de mulheres no pós-parto. Essa enfermidade tem potencialidade de se anunciar com variadas intensidades, o que se torna em um fator agravante do vínculo afetivo entre mãe-filho, uma vez que pode interferir na qualidade dos laços emocionais futuros. Fatores como reconhecimento do estado depressivo da mãe, acompanhamento das gestantes, a responsabilidade que o profissional tem em perceber esses distúrbios e vínculo afetivo/social/familiar são conceitos a serem aprofundados e vivenciados para melhor atendimento assistencial a esse público. Assim, sugere-se que outros trabalhos busquem o aprofundamento do tema e de cada um de seus conceitos que é de grande interesse para a sociedade.

\section{REFERÊNCIAS}

1. ALVES AM, et al. A enfermagem e puérperas primigestas: desvendando o processo de transição ao papel materno. Revista Cogitare Enfermagem. Campina Grande do Sul, v. 12, n. 4, p. 416-427, out./dez., 2007. Disponível em: http://ojs.c3sl.ufpr.br/ojs/index.php/ cogitare/article/view/10063. Acesso em 25 set. 2018.

2. BERETTA MIR. Tristeza/depressão na mulher: uma abordagem no período gestacional e/ou puerperal. Rev. Eletr. Enf. 2008;10(4):966-78. Disponível em: <https://www.fen.ufg.br/revista/v10/n4/pdf/v10n4a09.pdf> Acesso em 27 set. 2018.

3. BAPTISTA MN, et al. Associação entre suporte social, depressão e ansiedade em gestantes. Revista de Psicologia da Vetor Editora, v.7 n.1, p.39-48, Campinas-SP. 2006. Disponível em:< http://pepsic.bvsalud.org/pdf/psic/v7n1/v7n1a06.pdf>. Acesso em: 10 dez. 2016.

4. BRASIL. Resolução № 466, de 12 de dezembro de 2012. Dispõe sobre diretrizes e normas regulamentadoras das pesquisas envolvendo seres humanos. Disponível em: <ttp://conselho.saude.gov.br/resolucoes/2012/ Reso466.pdf. Acesso em 13 nov., 2018.

5. FONSECA MO, et al. Investigação dos fatores indicativos da depressão pós-parto em dois grupos de puérperas. Ciência Cuidado e Saúde, Maringá, v. 8, n. 3, p. 321-328, jul./set., 2009.

6. FONSECA VR, et al. Relação entre depressão pós-parto e disponibilidade emocional materna. Cad. Saúde Pública, Rio de Janeiro, v. 26, n. 4, abr. 2010.

7. GIL AC. Como elaborar projetos de pesquisa. 5. ed. São Paulo: Atlas, 2010.

8. NOELEN-HOEKSEMA S. Epidemiology and Theories of Gender Differences in Unipolar Depression. In M. V. Seeman (Ed.), Gender and Psychopathology (pp. 63-87). London: American Psychiatric Press Inc. 2010.

9. MINAYO MCS. Pesquisa social:Teoria Método e Criatividade.29 ed. Rio de Janeiro,2010.167 p.

10. MORAES IGS, PINHEIRORT, SILVARA, HORTA BL, SOUZAPLR, FARIA AD (2006). Prevalência da depressão pósparto e fatores associados. Revista de Saúde Pública, 40 (1), 65-70.

11. RIBEIRO WG, ANDRADE M. O papel do enfermeiro na prevenção da Depressão Pós-Parto (DPP). Informe-se em promoção da saúde, 2009. Disponível em: <http://www.uff.br/promocaodasaude/dpp3.pdf.> Acesso em: 30 set., 2018.

12. SANTOS Jr HPO. A trajetória de mulheres brasileiras na depressão pós-parto:o desafio de (re)montar o quebracabeça. [Tese]. São Paulo: Escola de Enfermagem, Universidade de São Paulo, 2013.

13. SCHARDOSIM JM, HELDTE. Escalas de rastreamento para depressão pós-parto: uma revisão sistemática. Revista Gaúcha de Enfermagem. Porto Alegre, v. 32, n. 1, mar. 2011. Disponível em: <http://www.scielo.br/scielo.php?script=sci_arttext\&pid=S1983-14472011000100021> Acesso em: 02 out. 2018.

14. SILVA FCS, et al. Depressão pós-parto em puérperas: conhecendo interações entre mãe, filho e família. Acta Paulista de Enfermagem, São Paulo, v. 23, n. 3 , jun. 2010. Disponível em: <http://www.scielo.br/pdf/ape/v23n3/v23n3a16.pdf> Acesso em: 26 set. 2018.

15. SOBREIRA N, PESSO ACG. Assistência de Enfermagem na Detecção da Depressão Pós-Parto.Revista Enfermagem Integrada - Ipatinga: Unileste-MG, v 5, n. 1, p. 905-918, Jul./Ago. 2012. Disponível em: https://www.unilestemg.br/ enfermagemintegrada/artigo/v5/04-assistencia-de-enfermagem-na-deteccao-da-depressao-pos-parto.pdf. Acesso em: 22 set. 2018.

16. VALENÇA CN, GERMANO RM. Prevenindo a Depressão Puerperal na Estratégia de Saúde da Família. Rev. Rene. Fortaleza, v. 11, n. 2, p. 129-139, abr./jun.2010. Disponível em: http://www.redalyc.org/pdf/3240/324027970015.pdf. Acesso em: 22 set. 2018. 